Tropical Journal of Pharmaceutical Research January 2016; 15 (1): 27-32

ISSN: $1596-5996$ (print); 1596-9827 (electronic)

(C) Pharmacotherapy Group, Faculty of Pharmacy, University of Benin, Benin City, 300001 Nigeria.

All rights reserved.

Available online at http://www.tjpr.org

Original Research Article

http://dx.doi.org/10.4314/tjpr.v15i1.4

\title{
Evaluation of Immunomodulatory Effect of Immunace on Adjuvanticity of 1,2-Dioleoyl-3- trimethylammoniumpropane-based Liposomes
}

\author{
Ebele Onuigbo $^{1 *}$, Austin Ngene $^{2}$, Vincent Okore ${ }^{1}$ and Anthony Attama ${ }^{1}$ \\ ${ }^{1}$ Department of Pharmaceutics, Faculty of Pharmaceutical Sciences, ${ }^{2}$ Department of Veterinary Surgery, University of Nigeria, \\ Nsukka, Nigeria \\ *For correspondence: Email: ebele.onuigbo@unn.edu.ng; Tel: +234-806-299-5712
}

Received: 8 September 2015

Revised accepted: 6 December 2015

\begin{abstract}
Purpose: To investigate the antibody effect of immunace on the adjuvanticity of 1,2-dioleoyl-3trimethylammoniumpropane (DOTAP)- based liposomes.

Method: The vesicles of the liposome-based ND vaccine were prepared by lipid film hydration method and physically characterized for shape, particle size and zeta potential. Forty experimental birds were divided into an unvaccinated group, a liposomal Newcastle disease (ND) vaccine group, combined liposomal $N D$ vaccine and immunace group, and a live La Sota $\Theta$ vaccine group. The liposomal ND vaccine, liposomal ND vaccine and immunace and a live $L a$ Sota ${ }^{8}$ vaccine groups were vaccinated orally at 3 and 6 weeks of age. Haemagglutination inhibition test was carried out after primary and booster doses.

Results: The $\log _{2}$ mean antibody titre induced by the liposomal ND vaccine after secondary immunization of the birds was $9.60 \pm 0.95$ while that of the combined liposomal ND vaccine and immunace group was $7.00 \pm 1.71$, and that of the live La Sota vaccine $\Theta$ was $6.00 \pm 0.63$. There was no detectable antibody in the unvaccinated group throughout the experiment. At $p<0.05$, the liposomal ND vaccine group, after secondary immunization, produced antibodies which were significantly higher than those of the combined immunace-liposomal ND vaccine group.

Conclusion: There was a boost in the immune response of the birds immunized with liposomal ND vaccine and immunace after primary immunization only.
\end{abstract}

Keywords: Antibody, Newcastle disease vaccine, La Sota, DOTAP, Immunace, Immunity, Adjuvant

Tropical Journal of Pharmaceutical Research is indexed by Science Citation Index (SciSearch), Scopus, International Pharmaceutical Abstract, Chemical Abstracts, Embase, Index Copernicus, EBSCO, African Index Medicus, JournalSeek, Journal Citation Reports/Science Edition, Directory of Open Access Journals (DOAJ), African Journal Online, Bioline International, Open-J-Gate and Pharmacy Abstracts

\section{INTRODUCTION}

Newcastle disease (ND) is a contagious and fatal viral disease affecting both wild and domestic avian species [1,2]. The impact of ND is most notable in controlled poultry due to its high susceptibility [2]. ND has been reported to represent a stronger drain on the world economy than any other animal viral disease. It is probably the most serious global disease of poultry. Vaccination programmes are now designed to hyperimmunize chickens effectively to protect them from field/virulent strains of the ND virus, and for the vaccines to be effective it is important that they are delivered properly and effectively.

Lately, the advances in dosage forms have resulted in the development and improvement of drug delivery systems. From earliest times, man has devised different approaches and mechanisms to introduce therapeutic agents into the body. Currently, the approaches have 
evolved into cutting-edge nanotechnologies that have improved drug release profile, absorption, targeting and overall bioavailability. Many medications such as peptides and proteins, antibody, vaccines, gene based drugs which are subject to enzymic degradation by proteinases, peptidases, nucleases etc have been protected by encapsulating in carriers like liposomes, niosomes, virosomes, dendrons, nanoemulsions, nanospheres and polymer based nanoparticles $[3,4]$. They are effective and they target the drug to specific sites for effective and safe delivery.

Vaccines are immunological products that are capable of inducing the production of antibodies. Vaccines based on recombinantly made subunit and synthetic- peptide antigens are usually nonimmunogenic, and the need for adjuvanticity is essential. They are however not ideal because they induce only humoral immunity but not cellmediated and cannot be lyophilized. Recently, there has appeared a vaccine adjuvant candidate, liposome, with a liposome-based vaccine (against hepatitis $A$ ) being licensed for use in humans [4,5].Vaccines based on novasomes (non-phospholipid liposomes formed from single-chain amphiphiles, with or without other lipids) have been licensed for the immunization of fowl against Newcastle disease virus and avian rheovirus [5,6]. Other liposomal or novasome-based vaccines against bacterial and viral infections are under development. Liposomes are biodegradable and non-toxic and can elicit both humoral and cell-mediated immunity and are easy to prepare [6,7].They are highly versatile in their structural characteristics which can be modified/manipulated to improve their adjuvanticity $[6,7,9]$, e.g. surface charge, lamellarity, fluidity, $\mathrm{pH}$ sensivity, vesicle size, antigen association, etc. There are detailed information available on the fate of liposomes after uptake by cells and the subsequent induction of cytotoxic T-lymphocyte responses. Liposomes are immunological adjuvants that are capable of augmenting immune responses to entrapped and surface-adsorbed antigens [8]. The basis for this immune-potentiating response lies in the natural targeting of liposomes to antigen-presenting cells (APC), most notably the macrophages $[9,15]$. Cationic liposomes are lipid-bilayer vesicle with a positive surface charge that has re-emerged as a promising new adjuvant technology $[10,17]$. Although there are some evidence that cationic liposome itself can improve the immune response against coadministered vaccine antigens, their main functions are to protect the antigens from clearance in the body and deliver the antigens to professional antigen presenting cells (APC) [11]. An immune booster immunace (Vitabiotics, UK) contains a comprehensive spectrum of antioxidants, vitamins and essential nutrients designed to maintain immune resistance and long-term cell protection (from free radicals and peroxides). Generally, immunace and other immune boosters increase the immunity of humans and animals by supplying the essential nutrients [12,24]. Immune boosters such as immunace are given for revitalization and improvement of the immune response, especially in those with low immunity. Immunace increases the amount of antibodies produced, by improving and maintaining the immune resistance [12]. In this study, the researchers combined two immune boosters, DOTAP-based liposome and immunace to know the effect of immunace on the established adjuvanticity of DOTAP.

\section{EXPERIMENTAL}

\section{Materials}

Cholesterol (Sigma grade, minimum purity $99 \%$; Sigma Aldrich Chemie, St Louis, Missouri, USA), DOTAP (Sigma-Aldrich, donation from Prof. Godwin Nchinda, Rockefeller University, New York, USA), phospholipon $90 \mathrm{H}$ (donation from Phospholipid GmbH Nattermannallee, Cologne, Riedel-de Haen, Seelze Germany), methanol(extra pure; ScharlauChemie S.A.), chloroform (Sigma-Aldrich GmbH, Germany), live La Sota ${ }^{\circledR}$ vaccine (National Veterinary Research Institute, Jos, Nigeria), Immunace .

\section{Preparation of the liposome suspension}

Lyophilized La Sota $^{\circledR}$ vaccine containing 200 doses/vial was reconstituted with phosphatebuffered saline by dissolving a vial in $40 \mathrm{ml}$ phosphate buffer solution. Then $196 \mathrm{mg}$ phosphatidylcholine, $96.7 \mathrm{mg}$ cholesterol and 50 $\mathrm{mg}$ DOTAP were dissolved in $3 \mathrm{~mL}$ chloroform/methanol system (2:1) in a roundbottom flask. The solvent mixture was evaporated at room temperature and the flask rotated until a smooth, thin, dry film was obtained on the wall of the flask $[13,26]$. Reconstituted vaccine $(5 \mathrm{ml})$ was used to hydrate the dry film and agitated gently until a milky colloidal dispersion was formed.

\section{Transmission electron microscopy}

The prepared liposome-encapsulated ND vaccines were processed using copper grids to adsorb the particles from the suspension, staining in $2.5 \%$ uranyl acetate for $30 \mathrm{sec}$ and 
drying. The specimens were observed under a JEM-1010 transmission electron microscope (JEOL, Tokyo, Japan) operated at $80 \mathrm{kV}$ at $x 10,500$ magnifications $[14,27]$.

\section{Vesicle size and zeta potential}

The $z$-average vesicle diameter and zeta potential of the ND vaccine liposomes in phosphate buffer solution ( $\mathrm{pH} 7.4)$ were determined by photon correlation spectroscopy using a nanosizer 3000 HS (Malvern Instruments, Malvern UK). The zeta potential was calculated from the mean of three runs. Each sample was diluted with bi-distilled water and the electrophoretic mobility determined at 25 ${ }^{\circ} \mathrm{C}$ and a dispersant dielectric constant of 78.5 and $\mathrm{pH}$ 7. The obtained electrophoretic mobility values were used to calculate zeta potentials using DTS software version 4.1 (Malvern Instruments) and applying Henry's equation $[15,28]$.

$\mathrm{UE}=\{2 \varepsilon Z f(K)\} / 3 \eta$

where $Z$ is the zeta potential, UE the electrophoretic mobility, $\varepsilon$ the dielectric constant, $\eta$ the viscosity of the medium and $f(K)$ is Henry's function.

\section{Vaccination schedule of the birds}

The chicks were raised from 1 day old until termination of the experiment. All bird handling and experiments were conducted following the guidelines stipulated by University of Nigeria Research Ethics Committee on animal handling and use. Eighty birds were divided into four groups of 20 birds each; the unvaccinated group, the liposomal ND vaccine group, the liposomal ND vaccine + immunace group and the La Sota ${ }^{\circledR}$ vaccine group. The different groups were kept in separate rooms before vaccination. The liposomal ND + immunace group was given 25 $\mathrm{mg} / \mathrm{mL}$ of immunace from day old to two weeks. At 2 weeks of age, all of the birds were tested for the absence of residual haemagglutination inhibiting $(\mathrm{HI})$ antibody to Newcastle disease.

At 3 weeks of age, the liposomal ND vaccine group and liposomal ND vaccine + immunace group were given $0.2 \mathrm{ml} / \mathrm{bird}$ (a dose) each of the liposomal ND vaccine orally while the La Sota ${ }^{\circledR}$ vaccine group were given $0.2 \mathrm{ml} / \mathrm{bird}$ (a dose) of the reconstituted La Sota ${ }^{\circledR}$ vaccine orally. The unvaccinated group served as the control. Two weeks after primary vaccination, $10 \mathrm{ml}$ of blood was withdrawn from the jugular vein and serum samples assessed for antibody to ND virus by haemagglutination inhibition $(\mathrm{HI})$ technique $[16,29]$. Booster vaccination was done at 6 weeks of age. Two weeks after secondary vaccination, all birds were bled and serum samples assessed for antibody to ND virus. The results are presented as the mean with standard deviation for each of the parameters.

\section{Data analysis}

The results are presented as $\log _{2}$ mean \pm standard deviation (SD). To determine statistically significant difference among the means, one-way analysis of variance was applied at $p<0.05$ using SPPS (version 16.0, SPSS Inc, USA).

\section{RESULTS}

\section{Transmission electron micrographs}

The technique used for the preparation of the liposomes was the lipid film hydration technique, which formed films on the walls of the flasks and on hydration produced a thick, gel-like, milky colloidal dispersion. The images of the vesicles, were closely packed and had near spherical shapes.

\section{Particle size}

The vesical size and zeta potential were evaluated using a zeta sizer. The mean size distribution and zeta potential were $<100 \mathrm{~d} . \mathrm{nm}$ and $24 \mathrm{mV}$ respectively.

\section{Immune response of the birds}

All the birds screened prior to administration of vaccine were negative for $\mathrm{HI}$ antibody. All control (unvaccinated) birds had no antibody throughout the experiment. The immune response of the birds is shown in Table 1. After primary vaccination, the liposomal ND vaccine + immunace group had the highest mean antibody titre $\left(\log _{2}\right)$ and standard deviation of $6.60 \pm 0.0$, the liposomal ND vaccine group had an antibody titre of $5.3 \pm 0.56$ while the La Sota ${ }^{\circledR}$ vaccine had a mean antibody titre of $5.50 \pm 0.67$ after primary immunization. After secondary vaccination the chickens further sero-converted, the liposomal ND vaccine had the highest mean antibody titre $\left(\log _{2}\right)$ of $9.60 \pm 0.95$ which was significantly higher than the liposomal ND + immunace group with a mean antibody titre of $7.00 \pm 1.71$ and the LaSota ${ }^{\circledR}$ vaccine group with $\left(\log _{2}\right) 6.00 \pm 1.30$. 
Table 1: Immune response of birds after primary and secondary immunization

\begin{tabular}{|c|c|c|c|}
\hline Treatment group & No. of chickens & $\begin{array}{l}\text { Primary immunization } \\
\left(\log _{2}\right) \pm S D\end{array}$ & $\begin{array}{c}\text { Secondary } \\
\text { immunization }\left(\log _{2}\right) \pm \\
\text { SD }\end{array}$ \\
\hline Unvaccinated control & 10 & $0.0^{A}$ & 0.0 \\
\hline Liposomal ND vaccine & 10 & $5.30+0.56^{\mathrm{b}}$ & $9.60+0.95^{\mathrm{C}}$ \\
\hline $\begin{array}{l}\text { LiposomalND+immunace } \\
\text { vaccine }\end{array}$ & 10 & $6.60+0.0^{\mathrm{B}}$ & $7.00+1.71^{\mathrm{b}}$ \\
\hline La Sota®vaccine & 10 & $5.50+0.67^{\mathrm{B}}$ & $6.00+1.30^{\mathrm{B}}$ \\
\hline
\end{tabular}

\section{DISCUSSION}

Liposomes are spherical vesicles composed of an aqueous core which is entirely enclosed by a membrane composed of phospholipids and cholesterol. When these lipids are exposed to an aqueous environment, interactions between themselves and with water lead to spontaneous formation of closed bilayers [17,30]. The fluidity or rigidity of the liposomal bilayer, when it is made from a single lipid depends on the lipid phase transition temperature (Tc) [18,31]. Increasing the temperature changes the membrane fluidity from a solid-gel phase, where the lipid hydrocarbon chains are in an ordered state, to a fluid liquid-crystalline phase, a disordered state, where molecules have more freedom of movement.

Membrane permeability is highest at the phase transition temperature, and is lower in the gel phase than in the fluid phase. A look at the liposomes showed vesicles that were mostly spherical in appearance, entrapping the vaccine within their core. The vesicles appeared tightly packed under the transmission electron microscope, indicating that the phosphatidylcholine, cholesterol and DOTAP, which are amphipathic lipids, thermodynamically organized themselves to form stable self-closed vesicles. The tight packing of the vesicles may also have reduced the binding/insertion of proteins, which normally destabilize membranes and mark liposomes for removal by phagocytic cells. Generally, the more ordered and hence tightly packed the membrane of a liposome, the less permeable it is $[19,32]$.

Particle size is also one of the determining factors for macrophage clearance. Therefore, large liposomes are rapidly removed from circulation. Photon correlation spectroscopy using a zetasizer is a technique that measures time-dependent fluctuations in the intensity of scattered light and was employed to measure size distribution of the particles. If the particle size of the liposomes is below $200 \mathrm{~d} . \mathrm{nm}$, it would escape phagocytosis and the circulation time will be prolonged $[20,33]$. If the circulation time is prolonged, there will be more contact time of the liposomes with the immune cells, resulting in higher immunity. Encapsulation of the ND vaccine in the liposomes may also have reduced the volume of distribution of the vaccine and increased targeting to the immune cells $[20,33]$.

Knowledge of the zeta potential of the liposomal ND vaccine would help to predict its fate in vivo. Positively charged liposomes will normally fuse with the negatively charged cells. Once internalized, the particles are offered to the continuous lymphoid tissue so as to protect the antigen against degradation on mucosal surfaces, and enhance its uptake in mucosaassociated lymphoid tissue. The vaccines used for ND control must be able to protect the susceptible poultry against velogenic strains of the virus. Antibody titres of $2^{3}$ are protective, but current poultry practices are now designed to hyperimmunize chickens to protect them more effectively from field/virulent strains of the ND virus $[21,34]$. This could be achieved by administering live plus inactivated vaccination to boost the antibody titres to as high as $2^{7}$.

In the study, the objective was to investigate the effect of immunace on the established immunoadjuvanticity of DOTAP. The primary immunization of immunace and DOTAP-based ND vaccine produced an antibody titre which was higher than DOTAP-based ND vaccine alone. After the secondary immunization, the antibody titre of DOTAP-based ND vaccine was significantly higher than DOTAP-based ND vaccine showing that immunace has a shortacting effect on the immune cells while DOTAP has a longer lasting effect on the immune cells. Immunoadjuvants are useful in low-biosecurity areas with high ND prevalence $[22,35]$. Liposomal ND vaccine, after secondary immunization, had a significant effect on the immune cells, inducing antibody titres as high as $2^{9}$. Association of antigen with liposomes has been known to allow the antigen to gain access to both the major histocompatibility (MHC) class I and class II pathways in antigen presenting cells 
(APCs). As a result, liposomal antigen can stimulate antibody production as well as cellular immune responses $[23,36]$.

\section{CONCLUSION}

DOTAP-based cationic liposome, based on the findings of this study, has demonstrated its ability to function as immune adjuvant. Immunace, on the other hand, demonstrated a short-lived coimmunoadjuvanting activity. There was no significant immunological relevance for combining DOTAP-based ND vaccine and Immunace since DOTAP-based cationic liposome still gave a significantly higher immune response after secondary immunization.

\section{ACKNOWLEDGEMENT}

The authors wish to thank Nattermann Koln, Germany for the gift of Phospholipon $90 \mathrm{H}$ and Professor Godwin Nchinda for donating DOTAP. The authors also want to thank the academic staff of the Faculty of Veterinary Medicine, University of Nigeria, Nsukka for assisting in the research work.

\section{CONFLICT OF INTEREST}

No conflict of interest associated with this work.

\section{CONTRIBUTION OF AUTHORS}

$\mathrm{EO}, \mathrm{VO}$ and $\mathrm{AA}$ designed this work, $\mathrm{VO}$ and $\mathrm{AA}$ supervised it while EO and AN collected and analysed the data and prepared the manuscript which was then approved by all authors.

\section{REFERENCES}

1. Seal BS, King DJ, Sellers HS. The avian response to Newcastle disease virus. Dev Comp Immunol 2000; 24 . 257-268.

2. Alexander DJ. Newcastle disease, other avian paramyxoviruses, and pneumovirus infections. In: Saif YM, Barnes HJ, Glisson JR, Fadly AM, McDougald LR, Swayne D, Eds. Diseases of Poultry, 11th edn, lowa State: Ames lowa State University Press; 2003. p. 6399.

3. Commelin, DJA. Active Targeting with particulate carrier system in the blood compartment. Adv Drug Rev 1995; 17(1): 50-58.

4. Gregoriadis G. Engineering liposomes for drug delivery: progress and problems. Trends in Biotech 1995; 13: 527-537.

5. Gupta RK, Varanelli CL, Griffin P, Wallach DF, Sibber GR. Adjuvant properties of non-phospholipid liposomes (novasomes) in experimental animals for human vaccine antigens. Vaccine 1997; 14: 219-225.

6. Gregoriadis G. Immunological adjuvants: a role for liposomes. Immunol Today 1990; 11: 89-97.

7. Nakanishi T, Kunisawa J, Hayashi A, Tsutsumi $Y$, Kubo $K$, Nakagawa S, Fujiwara H, Hamaoka T, Mayumi $T$. Positively charged liposomes function as an efficient immunoadjuvant in inducing immune responses to soluble proteins. Bioch Biophys Res Comm 1997; 240: 793-797.

8. Allison AC, Gregoriadis G. Liposomes as immunological adjuvants. Nature 1974; 252: 252.

9. Rao M, Alving CR. Delivery of lipids and liposomal proteins to the cytoplasm and Golgi of antigenpresenting cells. Adv Drug Deliv Rev 2000; 41: 171-188.

10. Jackers P. Liposomes: Anionic, Cationic and Non-ionic. $J$ Virol 1992; 66: 3899.

11. Bertram J. Formulation of Cationic Liposomes. Biochem Res Commun 1994; 200: 661.

12. Schmidtke JR, Johnson AG. Characteristics of Adjuvant Action on Antibody Synthesis. J Immunol 1971; 106: 1191-1200.

13. Azmin MN, Florence AT, Handjani-Vila RM, Stuart JFB, Vanlerberghe G, Whittaker JS. The effect of non-ionic surfactant vesicle (niosome) entrapment on the absorption and distribution of methotrexate in mice. $J$ Pharm Pharmacol 1985; 37: 237-242.

14. Chenatachan $P$, Akarachalanon $P$, Worawirunwory $D$, DararutanaP, Bangtrakulnonth $A$, Bunjop $M$, Kongmuang $S$. Ultrastructural characterisation of liposomes using transmission electron microscope. Adv Mater Res 2008; 55(57): 709-711.

15. Zetasizer Nano Series. Malvern Instruments, England. 2005, User Manual Issue 2.2

16. Office International des Epizooties (OIE) (World Organization of Animal Health). 2004. Manual of Standards of Diagnostic Tests and Vaccines

17. Frezard F. Liposomes: from biophysics to the design of peptide vaccines. Biol Res 1999; 32(2): 181-189.

18. Frézard F, Santaella C, Vierling P, Riess JG. 1994. Permeability and stability in buffer and in human serum of fluorinated phospholipid-based liposomes. Biochim Biophys Acta 1994; 1192: 61-70.

19. De Gier J, Mandersloot JG, Van Deenen LLM. Lipid composition and permeability of liposomes. Bioch Biophy Acta 1965; 150: 666-675.

20. Maurer N, Fenske DB,Cullis PR. Developments in liposomal drug delivery systems. Exp Opin Biol Ther 2001; 1(6): 1-25.

21. van Eck JHH. Protection of broilers against Newcastle disease by hyperimmunization of the dams. Vet Quarterly 1990; 12: 139-145.

22. Hutchinson HL. The control and eradication of Newcastle disease in Northern Ireland. The Veterin Rec 1975; 96 : 213-217.

23. Zhou F, Huang L. Liposome-mediated cytoplasmic delivery of proteins: an effective means of accessing the 
MHC class I restricted antigen presentation pathway. Immunomethods 1994; 4: 229-235.

24. Schmidtke JR, Johnson AG. Characteristics of Adjuvant Action on Antibody Synthesis. J Immunol 1971; 106: 1191-1200.

25. Namdeo A, Mishra PR, Khopade AJ, Jain NK. Formulation and evaluation of noisome encapsulated indomethacin. Indian Drugs 1999; 36(6): 378-380.

26. Azmin MN, Florence AT, Handjani-Vila RM, Stuart JFB, Vanlerberghe G, Whittaker JS. The effect of non-ionic surfactant vesicle (niosome) entrapment on the absorption and distribution of methotrexate in mice. $J$ Pharm Pharmacol 1985; 37: 237-242.

27. Chenatachan $P$, Akarachalanon $P$, Worawirunwory $D$, Dararutana $P$, Bangtrakulnonth $A$, Bunjop $M$, Kongmuang S. (2008). Ultrastructural characterisation of liposomes using transmission electron microscope. Adv Mater Res 2008; 55(57): 709-711.

28. Zetasizer Nano Series. Malvern Instruments, England. 2005, User Manual Issue 2.2

29. Office International des Epizooties (OIE) (World Organization of Animal Health). 2004. Manual of Standards of Diagnostic Tests and Vaccines

30. Frezard F. Liposomes: from biophysics to the design of peptide vaccines. Biol Res 1999; 32(2): 181-189.

31. Frézard F, Santaella C, Vierling P, Riess JG. 1994. Permeability and stability in buffer and in human serum of fluorinated phospholipid-based liposomes. Biochim Biophys Acta 1994; 1192: 61-70.

32. De Gier J, Mandersloot JG, Van Deenen LLM. Lipid composition and permeability of liposomes. Bioch Biophy Acta 1965; 150: 666-675.

33. Maurer N, Fenske DB, Cullis PR. Developments in liposomal drug delivery systems. Exp Opin Biol Ther 2001; 1(6): 1-25.

34. van Eck JHH. Protection of broilers against Newcastle disease by hyperimmunization of the dams. Vet Quarterly 1990; 12: 139-145.

35. Hutchinson HL. The control and eradication of Newcastle disease in Northern Ireland. The Veterinary Record 1975; 96: 213-217.

36. Zhou F, Huang L. Liposome-mediated cytoplasmic delivery of proteins: an effective means of accessing the MHC class I restricted antigen presentation pathway. Immunomethods 1994; 4: 229-235.

37. Mahato RI. Use of cationic lipids in drug delivery. Pharm Res 1992; 6: 201-232.

38. Friend DS, Papahadjopoulos D, Debs RJ. Endocytosis and intracellular processing accompanying transfection mediated by cationic liposomes. Biochim Biophys Acta 1996; 1278: 41-50.

39. Felgner PL, Gadek TR, Holm M. Lipofection: a highly efficient, lipid-mediated DNA-transfection procedure. Proc Natl Acad Sci USA 1987; 84: 7413-7417. 